\title{
Success of Electronic Government Project in Bangkok Metropolis: An ITPOSMO Approach
}

\author{
Krish Rugchatjaroen
}

\begin{abstract}
E-government uses the Information and Communication Technologies (ICTs) to improve public activities, bringing also a promise of greater organizational efficiency and effectiveness. The aim of this research is to study the gaps between the proposed design of electronic government activities and the real circumstances and physical environment of Intelligent Taxi Stands and Bangkok CCTV projects. Use the ITPOSMO checklist that investigates seven dimensions of electronic government, developed by Richard Heeks. The results showed that: 1) The gaps between reality and expectation regarding Intelligent Taxi Stands and Bangkok CCTV are quite large; the largest gap being resource requirements and resource allocation (notably time and money) and a smaller gap being the information dimension. When compared the gaps between these two projects, found that Intelligent Taxi Stand has wider gap than Bangkok CCTV in every dimension except the topic of other resources. 2) Both projects are evaluated success level in the level of expected to be complete failure. Intelligent Taxi Stand has an average overall score of 50.38 and Bangkok CCTV has an average overall score of 49.19 .
\end{abstract}

Index Terms-Electronic government, intelligent taxi stand, Bangkok CCTV, ITPOSMO.

\section{INTRODUCTION}

E-government involves more than just websites and emails or the processing transactions via the Internet. It is a dynamic mixture of structures and functions. E-government becomes a natural extension of the information technology revolution that has accompanied the knowledge society. E-government means adding five aspects, namely good governance, transparency, accountability, efficiency, effectiveness and citizen participation, into an evaluation of government performance [1].

E-government uses the Information and Communication Technologies (ICTs) to improve public activities, bringing also a promise of greater organizational efficiency and effectiveness. For this and other reasons, e-government projects are being implemented in developing and transitional economics and societies. It can be seen that many countries have extensively developed their e-government systems to provide services for their people.

In addition, there are several international organizations

Manuscript received May 4, 2014; revised July 11, 2014. This work was supported in part by the Department of Social Sciences, Faculty of Social Sciences and Humanities, Mahidol University, Thailand for financial support from $3 \%$ of faculty's budget.

Krish Rugchatjaroen is with the Department of Social sciences, Faculty of Social Sciences and Humanities, Mahidol University, Thailand (e-mail: krish.rug@mahidol.ac.th). such as OECD, EU and UNPAN that provide support for e-government development and measurement [2].

However, e-government projects should be evaluated in terms of its efficiency, effectiveness and success. There have been numerous attempts by previous researchers who investigated the success of previous projects in term of outcomes. Some of them presented a set of guidelines that could reduce gaps between an ideal and a practical plan in e-government design. Nevertheless, at present, the majority of e-government projects are failures. The cause of these failures is explained in Heek [3]: an oversize gap between project design and reality. Identifying the nature and dimension of these gaps is crucial in evaluating the success or failure of any e-government project.

Bangkok is the largest economic and population zone of Thailand. Like other capital cities, it has grand traffic congestion. One of the most important contributory reasons for the congestion in Bangkok is stopping/parking behavior including roadside stops, especially by public transporters. The Intelligent Taxi Stand project has been established to provide and accommodate passengers and taxis with proper stop areas. The aim of this project is to reduce traffic problems in Bangkok. Another big issue in Bangkok is safety and security of persons and property. Because of a high rate of criminal actions, Bangkok Metropolitan Administration plans to add CCTV surveillance cameras for monitoring and protecting life and assets of citizens.

This study discusses e-government implementation on Intelligent Taxi Stand and Bangkok CCTV projects in Bangkok to clarify the gaps between reality and design of these projects using the ITPOSMO. This design-reality gap clarification will help to reduce future risks in the project failure.

\section{PROJECT'S BACKGROUND}

\section{A. Background of Intelligent Taxi Stand}

In the past, taxis have been using radio booking systems but some parts of the Bangkok taxi fleet may benefit from vehicle tracking systems and more advanced dispatch systems using technologies developed locally. The Bangkok Metropolitan Administration used a basic system to developing taxi tracking, dispatch, and automated customer booking as part of the Intelligent Taxi Stand project. (see Fig 1.) This project does not seem to attract attention from city people.

\section{B. Background of Bangkok CCTV}

A massive camera surveillance project launched by Bangkok Metropolitan Administration will added Bangkok 
with 27,000 CCTV surveillance cameras (see Fig. 2.) within 2012 as part of an ambitious security and crime-fighting initiative. Residents of Bangkok are encouraged to the program and waiting for more install CCTVs. So far, the project is still not completed. In some areas that have been installed, if requested picture from the camera, we might found that unavailable or dummy camera.

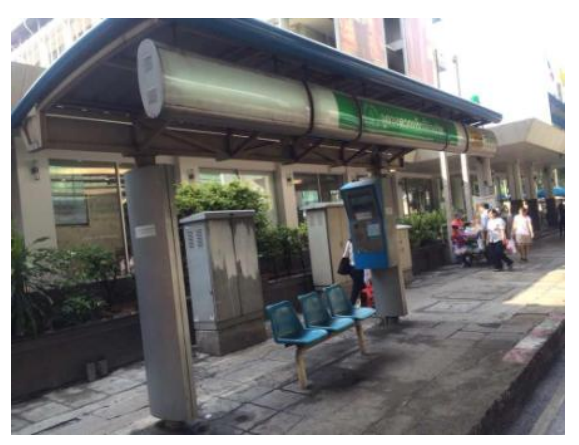

Fig. 1. Bangkok intelligent taxi stand.

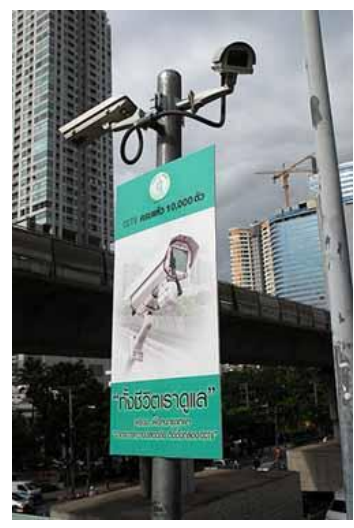

Fig. 2. Bangkok CCTV.

\section{MEthODOLOGY AND DATA ANALYSIS}

\section{A. Methodology}

This research utilizes several modes of data collection based on questionnaires that are developed by ITPOSMO model [3] which intends to illustrate the gap between reality and design of e-government via 7 aspects. (see Fig. 3.) These 7 aspects are 1) The information dimension: the system design assumed that its creation of formal strategic information would be value to functioning. In reality, informal information was what decision makers valued and used. 2) The technology dimension: the technology used in the project, comparing the requirement contained within the design of the e-government (project) application vs. the real situation. 3) The process dimension: the system design assumed that a rational model of structured decision-making. This mismatched the dominant reality of personalized, even politicized, unstructured decision-making. 4) The objectives and values dimension: the objectives and values that stakeholders need for successful of project implementation and application vs. current real objectives and values. 5) The staffing and skills dimension: skill levels/types required by the agency for their staffs. 6) The management systems and structures: the management systems and structures required in the project and 7) The other resources: involve in time, money and other resource that might be related to the success of project implementation and operation.

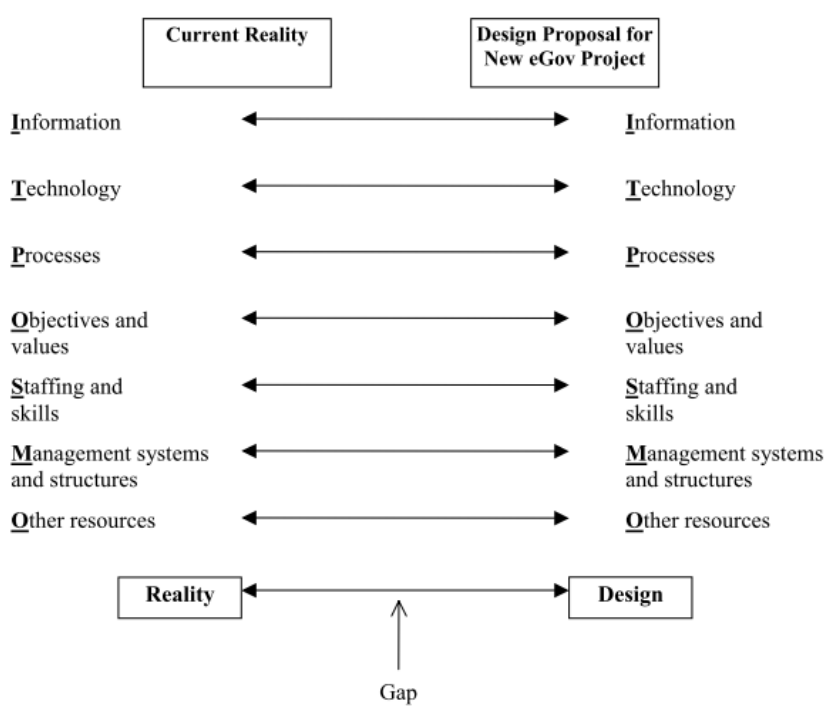

Fig. 3. ITPOSMO model.

This model assesses 'design-reality' gaps by rating numbers to indicate the size of the gap in each dimension using a scale from zero to ten. As a guide, please note that rating correspond to the following characteristics.

0 rating would indicate "no change between the design proposal and current reality"

5 rating would indicate "some degree of change between the design proposal anFd current reality"

10 rating would indicate "complete and radical change between the design proposal and current reality"

In presenting the results of project success from all seven dimensions, please note:

A value between 57-70 means the e-government project will almost certainly fail unless action is taken to close design-reality gaps.

A value between 43-56 means the e-government project may well fail unless action is taken to close design-reality gaps.

A value between 29-42 means the e-government might fail totally, or might well be a partial failure unless action is taken to close design-reality gaps.

A value between 15-28 means the e-government project might be a partial failure unless action is taken to close design-reality gaps.

A value between 0-14 means the e-government project well success

\section{B. Data Collection}

Four hundred local Bangkok people participated in answering the questionnaires regarding the Intelligent Taxi Stands and Bangkok CCTV. All of them are experienced in e-government projects.

\section{Reliability and Validly of Measures}

The measurement was conducted using confirmatory factor analysis; all items have a loading $\geq 0.3$. Kaiser-Myer-Olkin (KMO) test has a value of 0.89 . Whereas the internal consistency reliability of measure was tested using Cronbach's alpha and all items have values $\geq 0.7$. 


\section{Data Analysis}

The results were presented in average scale of each dimension and total scores of project success-failure evaluation will be presented in the next section. Independent sample t-test was used to analyses differentiate in total scores of project success-failure between Intelligent Taxi Stands and Bangkok CCTV.

\section{RESUltS AND CONCLUSION}

\section{A. Results}

The results were analyzed from the survey information and shown in all ITPOSMO gaps. It was found that those in Intelligent Taxi Stand project in itself show a wider gap than those in Bangkok CCTV, in itself. The specifics are as follows:

\section{1) Information gap}

This gap exists since the initiative project only involved with the government. A wide information gap occurred to both intelligent taxi stand (score $=6.97$ ) and Bangkok CCTV project (score $=6.79$ ). . This shown limitation of project information between governments to citizen.

\section{2) Technology gap}

Survey data shows a wide technology gap occurred in intelligent taxi stand (score $=7.16$ ) due to the mismatch of technologies used in this project. For Bangkok CCTV project it has a narrow gap (score $=6.92$ ) than another one. Current situation stated that the developer did not consider about maintenance for both software and hardware.

\section{3) Processes gap}

Aligned with technology gap, survey result shows that there was unclear of process dimension both of intelligent taxi stand (score $=7.14$ ) and Bangkok CCTV project (score = 7.04). Although it was argued that it had a clear project plan, there is no staff who deals with citizens. And there was stuck with the red tape of bureaucracy hierarchy.

\section{4) Objectives and values gap}

Gap in this area was widely. As in survey results, there was unclear of citizen participation in the projects' initiative and problem identification. Intelligent taxi stand (score $=7.12$ ) has wider gap than Bangkok CCTV (score $=6.96$ ) in this dimension. There have actual plans and strategies, but is found only a slogan and difficult to achieve without strong action.

\section{5) Staffing and skills gap}

There are no staff who deal with intelligent taxi stand and Bangkok CCTV implementation ready to give more information and they had not enough sufficient knowledge about the projects. However intelligent taxi stand (score = 7.17) has wider gap than Bangkok CCTV (score $=6.94$ ) in this dimension. This is mainly happened in developing countries where lack of qualified staff and training.

\section{6) Management systems and structures gap}

This section indicates lack of management system and structures required in the agency. Effective management structure should be considered by a significant issue for both projects. The results shown that intelligent taxi stand (score $=$ 7.40) has wider gap than Bangkok CCTV (score $=6.08$ ) in this dimension.

7) Other resources gap

There was a large other resources gap exists during the both project mainly about the budget problems. This was the only one dimension that Bangkok CCTV (score $=7.46$ ) has wider gap than intelligent taxi stand (score $=7.42$ ). Both projects seem to lose amount of money that the expenditure required for successful implementation.

\section{8) Project success}

Good management of these projects is essential if the government is going to be success in e-government implementation. From this research derived that both intelligent taxi stand (score $=50.38$ ) and Bangkok CCTV (score $=49.19$ ) may well fail unless action is taken to close design-reality gaps.

\section{9) Different of success level}

T-test compares the actual difference between two means level of success of the project. Intelligent Taxi Stand and Bangkok CCTV project also found that no significant difference appears between both projects.

\section{CONCLUSION}

This research describes and analyzes the gaps between reality and expectation within the Intelligent Taxi Stand project and also Bangkok CCTV. The gaps found are quite large; the largest gap is found within the resources dimension (including time and budget). The smallest gap exists within the information dimension. When comparing the gaps between these two projects, it can be found that Intelligent Taxi Stands have wider gap than Bangkok CCTV in every dimension except in the 'other resources' dimension. In terms of efficiency of the project, both projects are evaluated the level of success comparing to the level of expectation to complete with the failure risks. Intelligent Taxi Stand has an average overall score of 50.38 and Bangkok CCTV has an average overall score of 49.19. It shows that there are no difference between Intelligent Taxi Stand and Bangkok CCTV project success level.

From research in "Efficiency and CCTV in Crime Prevention and Suppression" [4], it showed the abilities of expanse area of CCTV cameras installing to prevent and suppress crime together with the number of CCTV cameras installed that were not much enough compared to the area of responsibility. Images remain sharp, frustration and lowquality CCTV cameras often indicated. Control authorities require 24-hour watch over, although the budget prepared for installation not include in maintenance. Technical staff should have been well-trained, but in fact the officers were advised in the initial deployment. It is possible that Bangkok CCTV cannot successfully meet the needs of citizens.

However, the Intelligent Taxi Stand project was found to be used less and less compared to the previous year. Percentage of number of customers felt from 38.6 to 35.9 in 2008 and 2009. Moreover, there are 12 stands that have never been used. It was not popular to be used because customers 
do not want to waste time waiting for. If they press bottom for a taxi through the system and another alternative taxi arrived first, they will take that one. This may be the prime reason that taxi stand projects fail [5]. Somboon et al. [6] studied the satisfaction of passengers using intelligent taxi services in Bangkok metropolis, and found 56 percent of samples seldom used it once per week. In addition, there was only a moderate level of satisfaction amongst the consumer public.

According to this analysis discussed above, there are some recommendations that can properly deal with the dimension of the ITPOSMO gaps. Firstly, management of time and budget should be improved; as well as practitioner team structure. A clear chain of command must exist to improve the project's efficiency and reliability. Second, it is also recommended for objective and even empowering citizen and government staffs to participate in the project processes with clearly understanding. Finally, the evaluation of e-government progress should not only be done once. It should be done for each part of the project to give a clear picture of success and failure of each project.

\section{APPENDIX}

\section{ITPOSMO checklist}

0 rating would indicate "no change between the design proposal and current reality"

5 rating would indicate "some degree of change between the design proposal and current reality"

10 rating would indicate "complete and radical change between the design proposal and current reality"

Dimension 1 Information:

1) What is the gap between the assumptions/requirements of the project system design about information quantity (how much information will be needed), and the quantity of information currently in use in reality in the public agency?

2) What is the gap between the assumptions/requirements of the project system design about information quality (how complete, accurate, relevant, timely and appropriately presented the information is), and the quality of information currently in use in reality in the public agency?

3) What is the gap between the assumptions/requirements of the project system design about information flows (how information moves from one person/office/organisation to another), and the flows of information currently in use in reality in the public agency?

Dimension 2 Technology:

1) What is the gap between the assumptions/requirements of the project system design about computer hardware (amount and type), and the computer hardware currently in use in reality in the public agency?

2) What is the gap between the assumptions/requirements of the project system design about computer software (amount and type), and the computer software currently in use in reality in the public agency?

3) What is the gap between the assumptions/requirements of the project system design about other technology (such as manufacturing or transportation technology), and the other technology currently in use in reality in the public agency??

Dimension 3 Process:

1) What is the gap between the assumptions/requirements of the project system design about core information-handling processes (used to capture, input, store, process and output data), and the core information-handling processes currently in use in reality in the public agency?

2) What is the gap between the assumptions/requirements of the project system design about decision processes (the how?, who? and when? of decisions), and the decision processes currently in use in reality in the public agency?

3) What is the gap between the assumptions/requirements of the project system design about action/transaction processes (e.g. putting decisions into action), and the action/transaction processes currently in use in reality in the public agency?

Dimension 4 Objectives and Values:

1) What is the gap between public participation that required for successful implementation of the project system design, and their current, real participation?

2) What is the gap between the objectives (i.e. goals or strategies) that required for successful implementation of the project system design, and their current, real objectives?

3) What is the gap between the values (i.e. organizational culture) that required for successful implementation of the project system design, and their current, real values?

Dimension 5 Staffing and Skills:

1) What is the gap between the technical skills required for successful implementation of the project system design, and current, real levels of technical skills in the public agency?

2) What is the gap between the operational skills required for successful implementation of the project system design, and current, real levels of operational skills in the public agency?

3) What is the gap between the awareness and knowledge required for successful implementation of the project system design, and current, real levels of awareness and knowledge in the public agency?

Dimension 6 Management Systems and Structures:

1) What is the gap between the management systems required for successful implementation of the project system design, and current, real management systems in the public agency?

2) What is the gap between the management structures required for successful implementation of the project system design, and current, real management structures in the public agency?

3) What is the gap between the informal systems and structures (e.g. those run by individuals for their own interests) required for successful implementation of the project system design, and current, real informal systems and structures in the public agency?

Dimension 7 Other Resources:

1) What is the gap between the expenditure required for successful implementation of the project system design, and current, real spent money? 
2) What is the gap between time required for successful implementation of the project system design, and current, real availability of time?

\section{REFERENCES}

[1] N. Mohammad, "Internal user' self-assessment of Malaysia's e-government flagship applications in lead implementation agencies," Ph.D. dissertation, Dept. Info. Sys., Isalamic Univ., Malaysia, 2008.

[2] K. Rugchatjaroen, "Electronic government in Thailand," Ph.D. dissertation, Dept. Soc. Sci., Ramkhamhang Univ., BKK, Thailand, 2010.

[3] H. Richard, "Information system and developing countries: failures, success, and local improvisations," in Proc. the IEEE Trans. on the Information Society, vol. 18, no. 2, pp. 101-112, 2002.

[4] U. Lertmoroskul, C. K. Suriyamanee, B. Siludomsup, S. Thongklom, O Chaona, D. Udomsup, and K. Kerdnoi, "Efficiency and CCTV in crime prevention and suppression," in Proc. the IEEE Trans. Journal of Thai Justice System, vol. 4, no. 3, pp. 5-44, 2011.
[5] 2007 Traffic Statistic, Traffic and Transport Department, 2007.

[6] R. Somboon, U. Nilrat, P. Metthanimitr, P. Suksamran, A. Thongnoi, and C. Suksantikarn, "The satisfaction of passenger that using intelligent taxi service a case study of chatujak district, Bangkok," M.S. thesis, Dept. Pub. Admin., Chandrakasem Rajabhat Univ., BKK, Thailand, 2005.

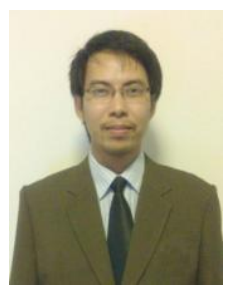

Krish Rugchatjaroen had fulfilled the Ph.D. in public administration at Ramkhamhaeng University, he is now working as a lecturer in Faculty of Social Science and Humanities, Mahidol University. His research is focused on areas related with information technology in the public sector, strategic management and public policy. His latest publication article was "The Success of Tourist Attractions Management Policy" in International Thai Tourism Journal, no. 1, vol. 8, January-June 2013 